\title{
Pengembangan Input Sistem Informasi Kesehatan Ibu dan Anak Berbasis Web di RSKIA Bhakti Ibu Yogyakarta
}

\author{
Julia Dian Pratiwi ${ }^{1}$, Nur Rokhman ${ }^{2}$ \\ Diploma III Rekam Medis Sekolah Vokasi Universitas Gadjah Mada ${ }^{1,2}$ \\ julia.dian.p@mail.ugm.ac.id ${ }^{1}$, nurrokhman@ymail.com ${ }^{2}$
}

\begin{abstract}
Abstrak
Latar Belakang: Buku Kesehatan Ibu dan Anak (KIA) merupakan alat yang digunakan untuk mencatat segala pelayanan kesehatan yang diberikan kepada ibu dan anak sejak ibu hamil, melahirkan, masa nifas, sampai anak berusia lima tahun dengan lengkap. Masih ditemui ibu-ibu hamil enggan membawa buku KIA, terkadang lupa membawa buku KIA ketika kontrol rutin, bahkan buku KIA yang dimilikinya pun hilang. Hal tersebut menyebabkan riwayat pencatatan pasien menjadi hilang. Pelayanan yang diberikan oleh tenaga kesehatan dimungkinkan menjadi tidak berkesinambungan dengan riwayat yang dimiliki pasien sebelumnya. Oleh karena itu, diperlukan sistem informasi agar mempemudah dalam pencatatan pelayanan kesehatan ibu dan anak, serta pihak rumah sakit memiliki back up data pasien.

Tujuan: Tujuan pada perancangan yaitu membuat input sistem informasi kesehatan ibu dan anak berbasis web di RSKIA Bhakti Ibu Yogyakarta.

Metode: Perancangan dilakukan menggunakan notepad++ dengan bantuan framework bootstrap untuk merancang antarmuka, framework codeigniter untuk koneksi dengan basis data, serta MySQL untuk membuat basis data.

Hasil: Hasil yang diperoleh adalah input dari sistem informasi kesehatan ibu dan anak. Input sistem terdiri dari menu pendaftaran pasien baru, catatan kehamilan, rencana persalinan, catatan kelahiran, catatan nifas, catatan pemeriksaan anak, catatan imunisasi, dan catatan pemberian vitamin A.

Kesimpulan: Perancang telah membuat input sistem informasi kesehatan ibu dan anak di RSKIA Bhakti Ibu Yogyakarta.
\end{abstract}

Kata kunci: sistem informasi, input, kesehatan ibu dan anak, rekam medis

\begin{abstract}
Background: "Buku KIA" is instrument used to record all health services given to mothers and children since mothers being pregnant, giving birth, having puerperium, until the child is five-year-old completely. There are still exists pregnant woman declined to use "Buku KIA", sometime forget to bring it when do routine control, and moreover the book has been missing. Because of that, medical record of the patient is missing. The services that given by health workers probably is not continuity with the previous services. Because of that the hospital needed an information system to ease recording the service of maternal and child health and also the hospital have a backup data of the patient.

Objective: The objective is to make an input system on maternal and child health information system web based in RSKIA Bhakti Ibu Yogyakarta.

Methods: The design is carried out using notepad++ with the help of bootstrap framework to design interface, codeigniter framework for connections with database, and MySQL to make database.

Results: The result is an input system of maternal and child health information system. The systems consist of some menus such as new patient registration, pregnancy notes, childbirth plan, birth notes, puerperium notes, notes of children checkup, immunization notes, and notes of vitamin A giving.

Conclusion: The designer has built an input system of maternal and child health information systems in RSKIA Bhakti Ibu Yogyakarta.

Keyword: information system, input, maternal and child health, medical record
\end{abstract}




\section{PENDAHULUAN}

Menurut Keputusan Menteri Kesehatan

Nomor 284 tahun 2004 tentang Buku Kesehatan Ibu dan Anak (KIA), menyatakan bahwa buku KIA merupakan alat yang digunakan untuk mencatat segala pelayanan kesehatan yang diberikan kepada ibu dan anak sejak ibu hamil, melahirkan, masa nifas, sampai anak berusia lima tahun secara lengkap. Buku KIA juga dijadikan sebagai pedoman dalam memberikan informasi yang dibutuhkan bagi ibu dan anak sejak ibu hamil, melahirkan, masa nifas, sampai anak berusia lima tahun pula. Serta buku KIA merupakan alat komunikasi antara ibu dan anak dengan tenaga kesehatan yang memberikan pelayanan kesehatan, sehingga pelayanan dapat diberikan secara berkesinambungan serta menghindari adanya faktor resiko yang membahayakan ibu maupun anak.

Buku KIA sangatlah penting, tidak hanya terkait pencatatan pelayanan kesehatan serta informasi-informasi terkait ibu dan anak. Buku KIA pun memuat cacatan mengenai keterangan lahir dan catatan imunisasi anak yang sangat penting bagi anak. Hal tersebut dikarenakan menurut Peraturan Walikota Yogyakarta Nomor 34 tahun 2014 tentang Pemanfaatan Buku Kesehatan Ibu dan Anak, menjelaskan bahwa buku KIA berfungsi sebagai syarat administrasi dalam pengurusan akta kelahiran dengan melampirkan catatan mengenai keterangan lahir anak. Serta catatan imunisasi anak yang terdapat di dalam buku KIA, berfungsi sebagai syarat administrasi bagi anak ketika anak hendak masuk sekolah dasar di wilayah Yogyakarta.

Walaupun begitu pentingnya buku KIA bagi ibu dan anak, akan tetapi fakta dilapangan masih ditemui ibu-ibu hamil enggan membawa buku KIA, terkadang lupa membawa ketika kontrol rutin, bahkan buku KIA yang dimilikinya pun hilang. Hal tersebut membuat riwayat pencatatan yang dimiliki ibu maupun anak menjadi hilang. Tindakan yang diberikan oleh tenaga kesehatan pun dimungkinkan terdapat ketidaksinambungan dengan riwayat yang dimiliki sebelumnya. Sehingga dimungkinkan pula terdapat faktor resiko yang dapat membahayakan kesehatan ibu maupun anak. Oleh karena itu, sangat disayangkan apabila buku KIA tersebut hilang dan informasi yang terdapat di dalamnya pun hilang.

Rumah Sakit Khusus Ibu dan Anak (RSKIA) Bhakti Ibu Yogyakarta belum menerapkan sistem rumah sakit. Kegiatan pelayanan di RSKIA Bhakti Ibu Yogyakarta masih dikerjakan secara manual pada setiap bagiannya. Berdasarkan wawancara dengan petugas RSKIA Bhakti Ibu Yogyakarta, dirasa perlu adanya pembuatan sistem informasi rumah sakit agar mempermudah dalam melaksanakan pekerjaan.

Zaki (2007), menyatakan bahwa cara manual dianggap tidak efektif dan efisien. Sehingga dibutuhkan adanya sebuah sistem informasi agar dengan mudah menjamin ketersediaan data dan informasi yang terkait kesehatan ibu dan anak. Hal tersebut sesuai dengan Respati (2010), bahwa diperlukan sebuah sistem informasi yang dapat mengelola data-data yang berhubungan dengan kesehatan ibu dan anak agar kualitas informasi kesehatan ibu dan anak dapat terjamin ketersediaannya.

Pembuatan sistem informasi kesehatan ibu dan anak berbasis web ini bertujuan agar pihak rumah sakit memiliki segala pencatatan terkait ibu dan anak yang tersimpan dalam basis data sistem informasi. Serta membantu pemilik buku KIA agar dapat mengakses segala pencatatan dan informasi yang terdapat di dalam buku KIA dan tersimpan dalam sistem informasi kesehatan ibu dan anak melalui jaringan internet tanpa batasan waktu dan tempat.

\section{METODE}

Perancangan dilakukan dengan menggunakan notepad++ dan bantuan framework bootstrap untuk merancang antarmuka, framework codeigniter untuk koneksi dengan basis data, serta MySQL untuk membuat basis data

\section{HASIL DAN PEMBAHASAN}

Perancangan diawali dengan tahap identifikasi kebutuhan sistem. Identifikasi kebutuhan sistem dilakukan dengan cara wawancara, observasi, dan studi dokumentasi terhadap buku Kesehatan Ibu dan Anak. Adapun alur pelayanan yang ada di RSKIA Bhakti Ibu Yogyakarta dapat dilihat pada gambar 1. 


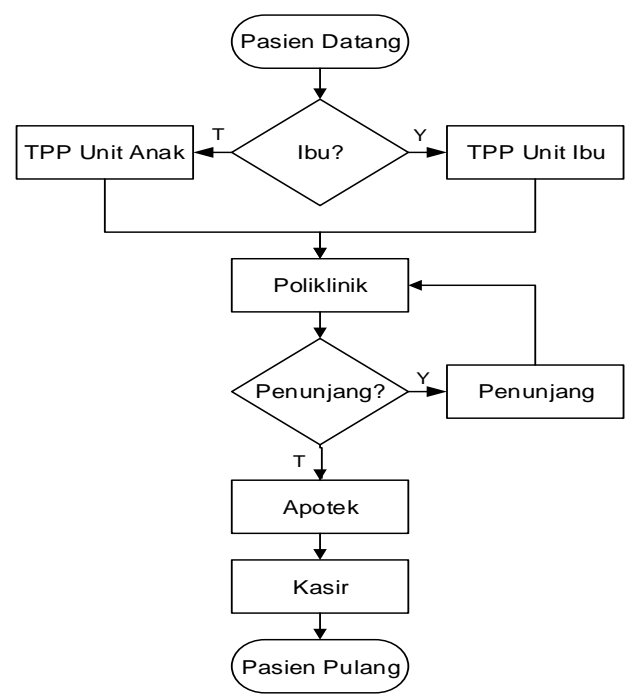

Gambar 1. Alur Pelayanan di RSKIA Bhakti Ibu Yogyakarta

Tahap analisis kebutuhan dilakukan dengan cara wawancara terhadap petugas rekam medis, observasi, serta studi dokumentasi di RSKIA Bhakti lbu Yogyakarta. Berdasarkan hasil wawancara, observasi, serta studi dokumentasi, dapat disimpulkan bahwa dibutuhkan catatan mengenai kesehatan ibu dan kesehatan anak. Catatan kesehatan ibu terdiri dari pencatatan pemeriksaan kehamilan rutin, pencatatan pemeriksaan nifas, dan rencana persalinan. Catatan kesehatan anak terdiri dari pencatatan pemeriksaan anak, pencatatan pemberian imunisasi, pencatatan pemberian vitamin $A$, serta pencatatan keterangan lahir.

Tahap perancangan selanjutnya yaitu merancang desain Entity Relational Diagram (ERD). ERD merupakan suatu model untuk menjelaskan hubungan data-data yang terdapat pada basis data sistem kesehatan ibu dan anak. ERD dari basis data sistem kesehatan ibu dan anak dapat dilihat pada gambar 2.

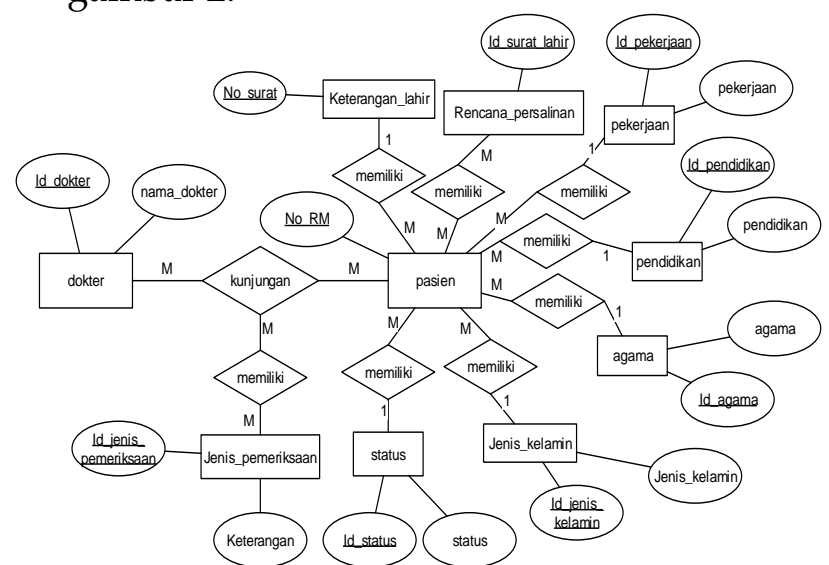

Gambar 2. ERD Sistem Informasi Kesehatan Ibu dan Anak
Setelah membuat desain ERD, tahap selanjutnya yaitu membuat Diagram Alir Data (DAD) dari sistem informasi kesehatan ibu dan anak. Pembuatan DAD sistem informasi kesehatan ibu dan anak terdiri dari beberapa tahap, yaitu diagram konteks, DAD level 0, DAD level 1, dan DAD level 2.

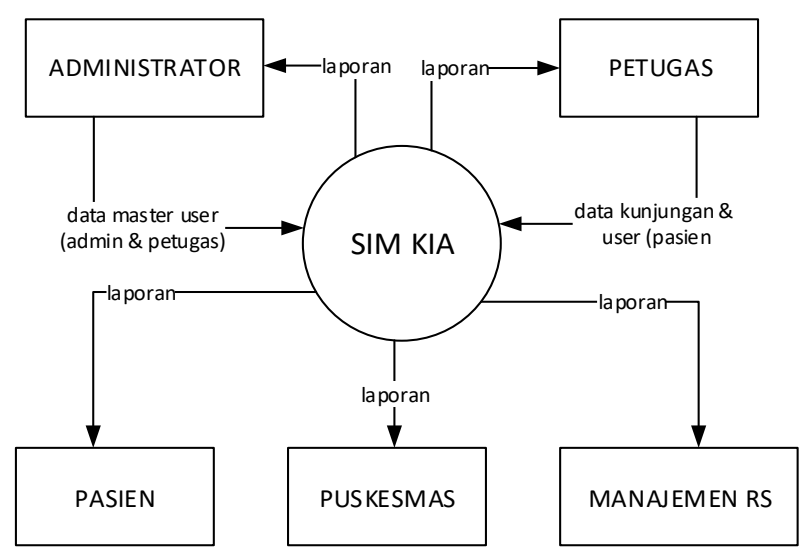

Gambar 3. Diagram Konteks Sistem Informasi Kesehatan Ibu dan Anak

Diagram konteks menunjukkan alur proses pada sistem kesehatan ibu dan anak secara umum. Terdapat lima entitas yang secara operasional berhubungan langsung dengan sistem kesehatan ibu dan anak. Entitas - entitas tersebut yaitu administrator, petugas, manajemen RS, puskesmas, dan pasien. Entitas administrator dan entitas petugas mempengaruhi aliran data masuk dan menerima aliran data dari sistem. Sedangkan entitas manajemen RS, entitas puskesmas, dan entitas pasien merupakan penerima aliran data dari sistem.

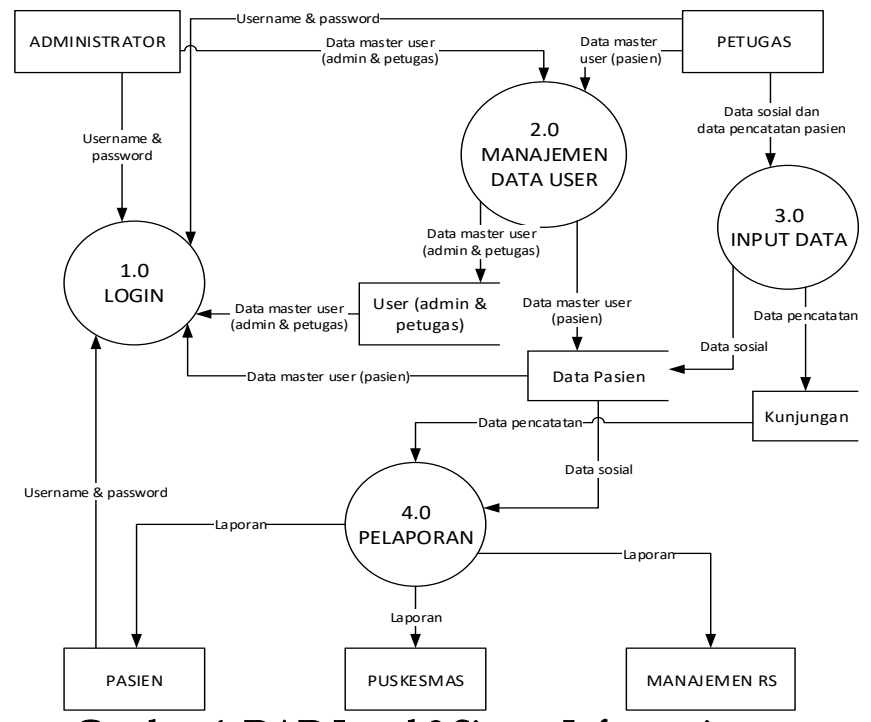

Gambar 4. DAD Level 0 Sistem Informasi Kesehatan Ibu dan Anak 
Diagram Alir Data (DAD) level 0 menggambarkan proses pertama dari setiap proses pengolahan data. Terdapat empat proses utama dalam sistem kesehatan ibu dan anak, yaitu proses login (1.0), proses manajemen data user (2.0), proses input data (3.0), dan proses pelaporan (4.0). Perancang hanya membahas input sistem kesehatan ibu dan anak, sehingga perancang tidak membahas proses pelaporan (4.0).

Proses login (1.0) akan menerima masukan data berupa username dan password dari entitas administrator, petugas, dan pasien. Proses login (1.0) akan melakukan pengecekkan data dengan mangambil data dari tabel user (admin dan petugas) dan tabel data pasien. Proses manajemen data user (2.0) akan menerima data master user (admin dan petugas) dari administrator dan akan disimpan di tabel user (admin dan petugas). Proses manajemen data user (2.0) juga akan menerima data master user (pasien) dari entitas petugas dan akan disimpan ke dalam tabel data pasien. Proses input data (3.0) akan menerima data sosial dan pencatatan dari entitas petugas. Data sosial akan disimpan di tabel data pasien, sedangkan data pencatatan akan disimpan di tabel kunjungan.

Diagram Alir Data (DAD) level 1 merupakan penjabaran dari proses manajemen data user (2.0) dan proses input data (3.0). Diagram Alir Data level 2 input data merupakan proses yang lebih spesifik dari proses input data. Terdapat empat proses pada DAD level 2. Proses tersebut yaitu manajemen data user (admin \& petugas), manajemen data user (pasien), input data sosial pasien, input data pencatatan $\mathrm{ibu}$, dan input data pencatatan anak.

Tahap perancangan selanjutnya adalah membuat desain basis data. Adapun relasi antar tabel dari basis data sistem informasi kesehatan ibu dan anak dapat dilihat pada gambar 5 .

Basis data sistem kesehatan ibu dan anak terdiri dari beberapa tabel. Setiap tabel memiliki kunci primer atau Primary Key (PK) masing-masing. Terdapat tabel master dan tabel transaksi pada relasi antar tabel basis data sistem kesehatan ibu dan anak. Tabel master yaitu tabel status, agama, jenis kelamin, pendidikan, pekerjaan, dokter, dan jenis pemeriksaan. Tabel transaksi yaitu tabel data pasien, kunjungan, rencana persalinan, keterangan lahir, dan user.

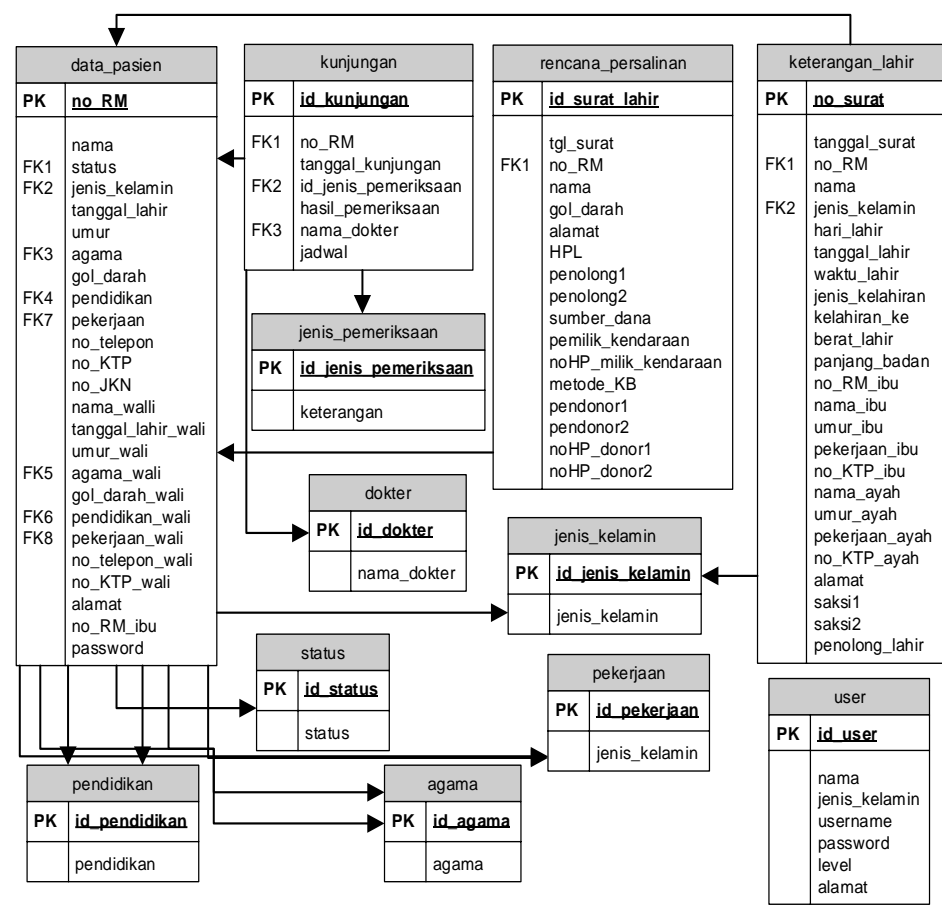

Gambar 5. Relasi Antar Tabel dari Basis Data

Sistem Informasi Kesehatan Ibu dan Anak

Berikut merupakan perwujudan rancangan menjadi sistem informasi kesehatan ibu dan anak. Uji coba dalam memasukkan data pada setiap item pada rancangan sistem ini tidak menggunakan data yang sebenarnya.

Halaman login digunakan untuk masuk ke dalam sistem sesuai dengan hak akses yang dimiliki oleh setiap pengguna. Halaman login pada sistem kesehatan ibu dan anak dapat dilihat pada gambar 6 .

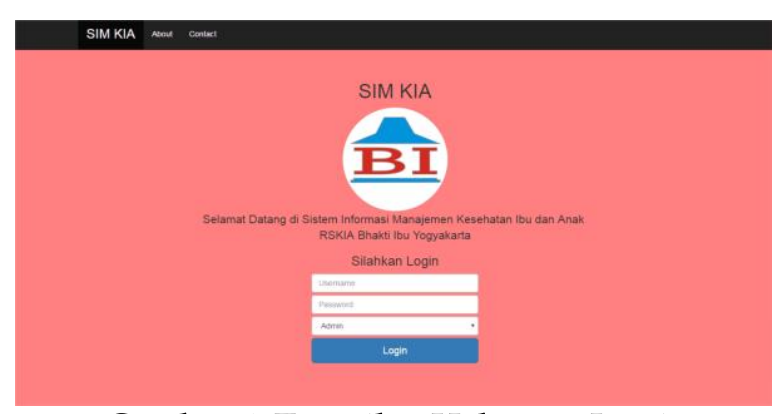

Gambar 6. Tampilan Halaman Log in

Terdapat kolom untuk mengisi username dan password, dimana password akan terisi dengan tanda bintang, seperti pada gambar 7 . 
Pengembangan Input Sistem Informasi Kesehatan Ibu Dan Anak...

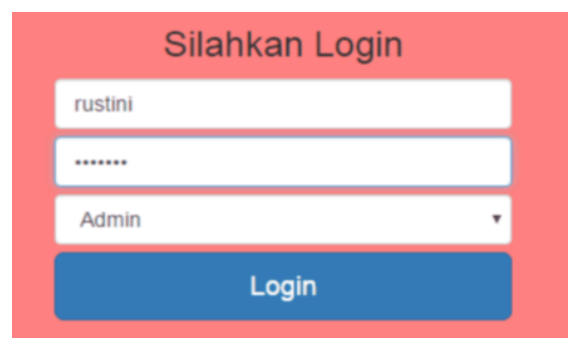

Gambar 7. Uji Coba Proses Login

Setiap kolom username dan password harus diisi. Apabila salah satu atau kedua kolom tidak terisi, maka akan muncul peringatan bahwa kolom harus diisi seperti pada gambar 8 .

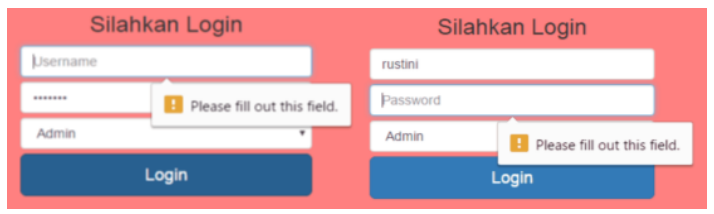

Gambar 8. Peringatan Kolom Tidak Terisi

Apabila username dan password tidak ditemukan oleh sistem, maka akan muncul peringatan keamanan bahwa pengguna tidak terdaftar seperti pada gambar 9 .

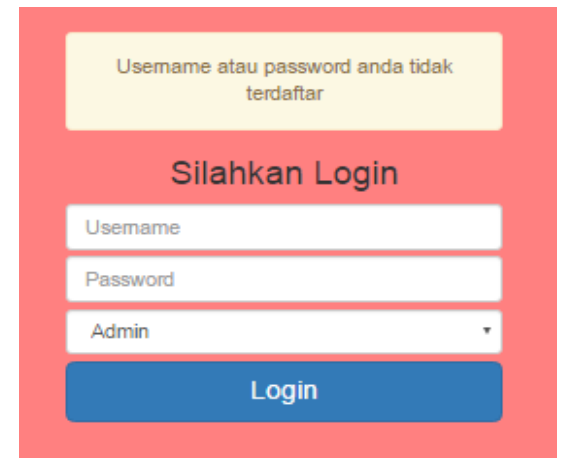

Gambar 9. Peringatan Keamanan Pengguna tidak Terdaftar

Apabila username dan password benar atau ditemukan oleh sistem, maka pengguna akan dapat mengakses sistem sesuai dengan hak akses yang dimilikinya.

Halaman login pada sistem kesehatan ibu dan anak ini sudah sesuai dengan Whitten dkk (2004). Menurut Whitten dkk (2004), sebelum masuk ke dalam sistem, pengguna harus diautentikasi dan diautorisasi oleh sistem terlebih dahulu. Sebagian besar login membutuhkan user id dan password, dimana password dicetak sebagai asterisk (tanda bintang). Apabila user id dan password pengguna tidak ditemukan oleh sistem, maka security authorization dialogue (peringatan keamanan) akan muncul. Apabila user id dan password pengguna ditemukan oleh sistem, maka akses pengguna dan hak layanan terhadap sistem ini harus terbuka.

Pengguna yang berhasil melakukan login akan masuk ke dalam sistem kesehatan ibu dan anak. Terdapat beberapa menu, yaitu menu dashboard, menu pendaftaran, menu catatan kesehatan yang terdiri dari catatan kesehatan ibu dan catatan kesehatan anak, menu laporan, serta menu surat keterangan lahir. Setiap menu yang terletak pada bagian sebelah kiri sistem, akan menavigasikan pengguna pada halaman yang berbeda-beda. Sebagai contohnya dapat dilihat pada halaman catatan kehamilan pada gambar 10 dan 11. Menu catatan kehamilan akan menavigasikan pengguna ke halaman catatan kehamilan.

Halaman catatan kehamilan terdiri dari bagian data sosial dan bagian pencatatan kesehatan. Bagian data sosial digunakan untuk melihat serta mengedit data sosial pasien. Bagian data sosial pasien akan terisi secara otomatis sesuai dengan data pasien yang dipilih sebelumnya pada daftar pasien. Terdapat dua pilihan bagian pada bagian pencatatan kesehatan, yaitu bagian riwayat kehamilan dan bagian pemeriksaan rutin. Bagian riwayat kehamilan yaitu gambar 10, digunakan oleh petugas untuk menyimpan catatan mengenai data-data riwayat kehamilan yang dimiliki ibu pada kunjungan pertama pada setiap kehamilan. Bagian catatan pemeriksaan rutin, yaitu gambar 11, digunakan untuk menyimpan catatan mengenai data-data pemeriksaan rutin ibu pada setiap kunjungan bulanannya.

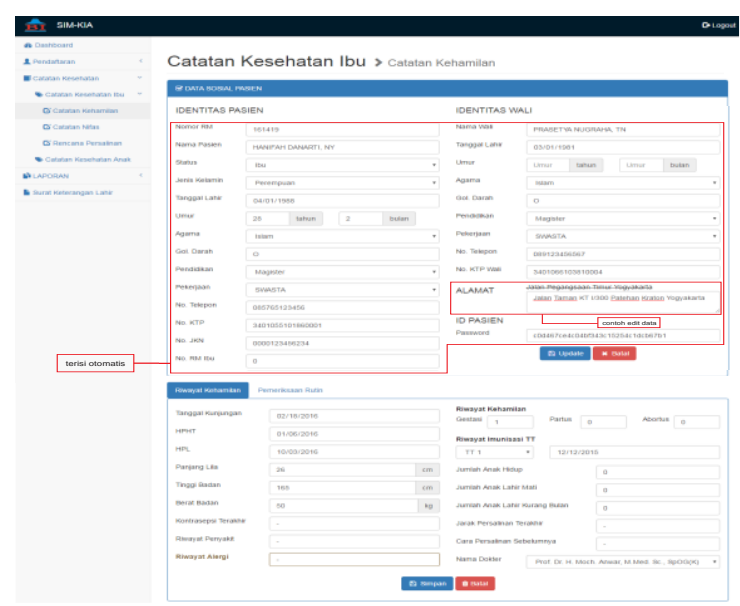

Gambar 10. Tampilan Halaman Catatan Kehamilan Bagian Riwayat Kehamilan 


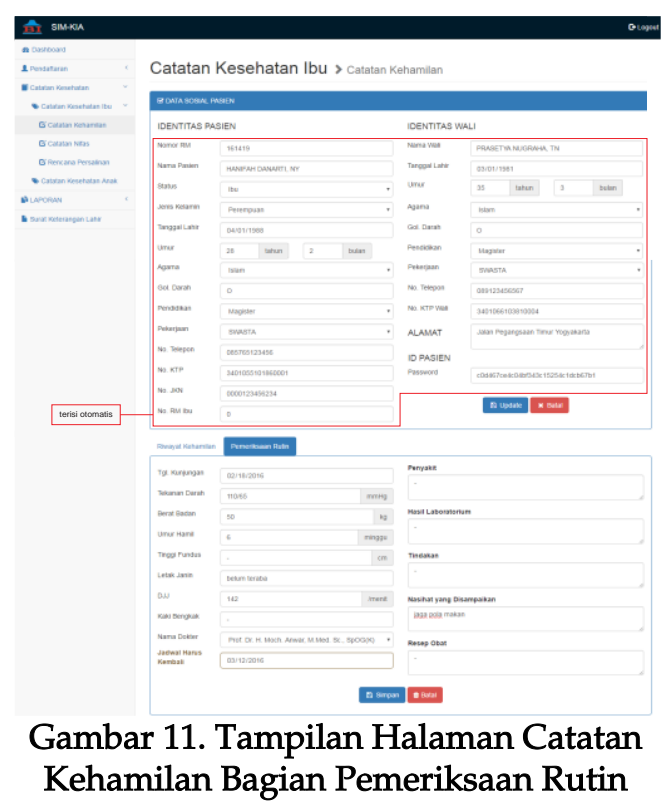

Sistem kesehatan ibu dan anak ini menggunakan menu hypertext dan hyperlink. Sistem kesehatan ibu dan anak berbasis web ini sudah sesuai dengan Whitten dkk (2004). Menurut Whitten dkk (2004), menyatakan bahwa menu hypertext dan hyperlink merupakan produk antarmuka pengguna berbasis web kontemporer. Hypertext dan hyperlink ditujukan untuk menavigasi halaman situs web. Apabila hyperlink di klik maka akan menavigasikan pengguna ke halaman yang terkait (atau bookmark pada sebuah halaman). Hypertext dan hyperlink digunakan untuk mengimplementasikan menu-menu pada body halaman web. Masing-masing pilihan menu merupakan frasa hypertext (atau icon atau tombol yang telah di-hyperlink) yang meminta aksi ke halaman web lainnya.

\section{PENUTUP}

A. Kesimpulan

Diperoleh input sistem informasi kesehatan ibu dan anak berbasis web di RSKIA Bhakti Ibu Yogyakarta.

B. Saran

Sebaiknya sistem informasi kesehatan ibu dan anak berbasis web dapat diimplementasikan di RSKIA Bhakti Ibu Yogyakarta agar catatan kesehatan ibu dan anak terdokumentasikan dengan baik didalam sistem.

\section{DAFTAR PUSTAKA}

Depkes RI. (2004). Keputusan Mentri Kesehatan Nomor 284 tahun 2004 tentang buku Kesehatan Ibu dan Anak (KIA).

Republik Indonesi, Peraturan Walikota Yogyakarta Nomor 34 tahun 2014 tentang Pemanfaatan Buku Kesehatan Ibu dan Anak.

Jeffery L. Whitten, Lonnie D. Bentley, Kevin C. Dittman. (2004). Metode Desain dan Analisis Sistem. Indonesia: Penerbit ANDI bekerjasama dengan McGra-Hill Education.

Zaki, Dwi Rahmi. (2007). Pengembangan Sistem Informasi Program Kesehatan Ibu dan Anak (KIA) di Dinas Kesehatan Kota Tanjung Balai Sumatera Utara tahun 2007. Tesis. S2 Ilmu Kesehatan Masyarakat, Universtas Gadjah Mada.

Respati, Dian Laela. (2010). Pengembangan Sistem Informasi Manajemen Kesehatan Ibu dan Anak di Puskesmas. Tesis. S2 Magister Teknologi Informasi, Universitas Gadjah Mada. 